\title{
A temporary social parasite of tropical plant-ants improves the fitness of a myrmecophyte
}

\author{
Alain Dejean \& Céline Leroy \& Bruno Corbara \& Régis Céréghino \& Olivier Roux \& \\ Bruno Hérault \& Vivien Rossi \& Roberto J. Guerrero \& Jacques H. C. Delabie \& \\ Jérôme Orivel \& Raphaël Boulay
}

\begin{abstract}
Myrmecophytes offer plant-ants a nesting place in exchange for protection from their enemies, particularly defoliators. These obligate ant-plant mutualisms are common model systems for studying factors that allow horizontally transmitted mutualisms to persist since parasites of ant-myrmecophyte mutualisms exploit the rewards provided by host plants whilst providing no protection in return. In pioneer formations in French Guiana, Azteca alfari and Azteca ovaticeps are known to be mutualists of myrmecophytic Cecropia (Cecropia ants). Here, we show
\end{abstract}

A. Dejean $(\star x) \bullet$ C. Leroy $\bullet$ O. Roux $\bullet$ J. Orivel

CNRS; Écologie des Forêts de Guyane (UMR-CNRS 8172),

Campus Agronomique,

97379 Kourou Cedex, France

e-mail: alain.dejean@wanadoo.fr

B. Corbara

CNRS; UMR 6023, Laboratoire Microorganismes Génome et

Environnement (LMGE),

63177 Aubière, France

B. Corbara

Clermont Université, Université Blaise Pascal, LMGE,

BP 10448, 63000 Clermont-Ferrand, France

R. Céréghino

CNRS; UMR 5245,

EcoLab (Laboratoire d'Ecologie Fonctionnelle),

31055 Toulouse, France

R. Céréghino

Université de Toulouse; UPS, INPT; EcoLab,

118 route de Narbonne,

31062 Toulouse, France

B. Hérault

Université des Antilles et de la Guyane; Écologie des Forêts de Guyane (UMR-UAG 43), Campus Agronomique,

97379 KOUROU cedex, France that Azteca andreae, whose colonies build carton nests on myrmecophytic Cecropia, is not a parasite of AztecaCecropia mutualisms nor is it a temporary social parasite of A. alfari; it is, however, a temporary social parasite of A. ovaticeps. Contrarily to the two mutualistic Azteca species that are only occasional predators feeding mostly on hemipteran honeydew and food bodies provided by the host trees, A. andreae workers, which also attend hemipterans, do not exploit the food bodies. Rather, they employ an effective hunting technique where the leaf margins are

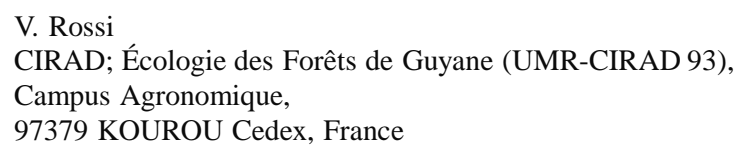

\section{R. J. Guerrero}

Grupo de Investigación en Insectos Neotropicales, INTROPIC, Universidad del Magdalena, Carrera 32 \# 22-08, San Pedro Alejandrino, Santa Marta, Magdalena, Colombia

J. H. C. Delabie

Laboratório de Mirmecología, Convênio UESC-CEPEC, Centro de Pesquisas do Cacau, CEPLAC,

Caixa Postal 7,

456000-000 Itabuna-BA, Brazil

R. Boulay

Estación Biológica de Doñana, CSIC,

Apdo. 1056,

41013 Sevilla, Spain

\section{R. Boulay}

Departamento de Biología Animal, Facultad de Ciencias, Universidad de Granada, 18071 Granada, Spain 
fringed with ambushing workers, waiting for insects to alight. As a result, the host trees' fitness is not affected as A. andreae colonies protect their foliage better than do mutualistic Azteca species resulting in greater fruit production. Yet, contrarily to mutualistic Azteca, when host tree development does not keep pace with colony growth, A. andreae workers forage on surrounding plants; the colonies can even move to a non-Cecropia tree.

Keywords Ant-plant relationships · Biotic defense . Parasites of mutualisms - Temporary social parasites . Azteca $\cdot$ Cecropia

\section{Introduction}

Ant-plants or "myrmecophytes" live in mutualisms with a limited number of plant-ants that they shelter in domatia (i.e., hollow branches or thorns and leaf pouches) and usually provide with food through extrafloral nectar and/or food bodies (FBs). In turn, plant-ants protect their host myrmecophytes from several kinds of enemies, particularly defoliators that they eliminate through their predatory and/or territorial behavior (Dejean et al. 2007; Rico-Gray and Oliveira 2007). Also, many plant-ants attend sap-sucking hemipterans for their honeydew.

Because the transmission of this mutualism is horizontal, the partners need to renew their association at the sapling stage of the plant and each time a guest colony dies as in most cases myrmecophytes live longer than their mutualist ants (except for those plant-ants that have evolved a strategy of secondary polygyny to ensure longer colony life spans). This situation permits other ant species to shortcircuit these associations and to exploit the rewards provided by the plant whilst providing nothing in return (Rico-Gray and Oliveira 2007). These species are called "cheaters" (i.e., having evolved from former mutualists) or "parasites" of the mutualism (i.e., exploiters with no mutualistic ancestor) (Janzen 1975; Gaume and McKey 1999; Bronstein 2001; Raine et al. 2004; Clement et al. 2008; Heil et al. 2009; Kautz et al. 2009; see also Wilkinson and Sherratt 2001).

We studied the ecology and behavior of Azteca andreae, which is specifically associated with two myrmecophytes: Cecropia obtusa and Cecropia palmata (Cecropiaceae). In the area studied in French Guiana, these Cecropia house colonies of two plant-ant species, Azteca alfari and Azteca ovaticeps, in their hollow trunks and branches, and provide them with glycogen-rich FBs and lipid-rich pearl bodies (see Davidson 2005; plant-ants associated with Cecropia are frequently called "Cecropia ants"). Like other Azteca, associated or not with myrmecophytes, the workers of these two mutualistic species prey on insects landing on the foliage of their host trees (Cabrera and Jaffe 1994; Dejean et al. 2009). A. andreae workers, however, build external, ovoid carton nests, and, rather than exploiting the FBs furnished by their host Cecropia, they frequently hunt large prey by ambushing side-by-side beneath the leaf margins, mandibles wide open (Fig. 1; Dejean et al. 2010). Also, A. andreae belongs to the aurita group that is composed of species thought to be temporary social parasites of other

Fig. 1 a A recently captured wasp is spread-eagled by a group of workers as nestmates begin to replace them in ambushing along the leaf margin. b Photo showing the beginning of the construction of a new A. andreae nest just under the crown of leaves while the old one is still being used; indeed, the nest position changes as the trees grow. Note that most of the leaf margins are fringed with ambushing workers. c Illustration of the technique used to evaluate the number of $\mathrm{A}$. andreae workers per centimeter of leaf margin: we photographed the workers ambushing from beneath the Cecropia obtusa leaves while cautiously placing a ruler 1-2 cm away from the leaf margins so as not to perturb the workers
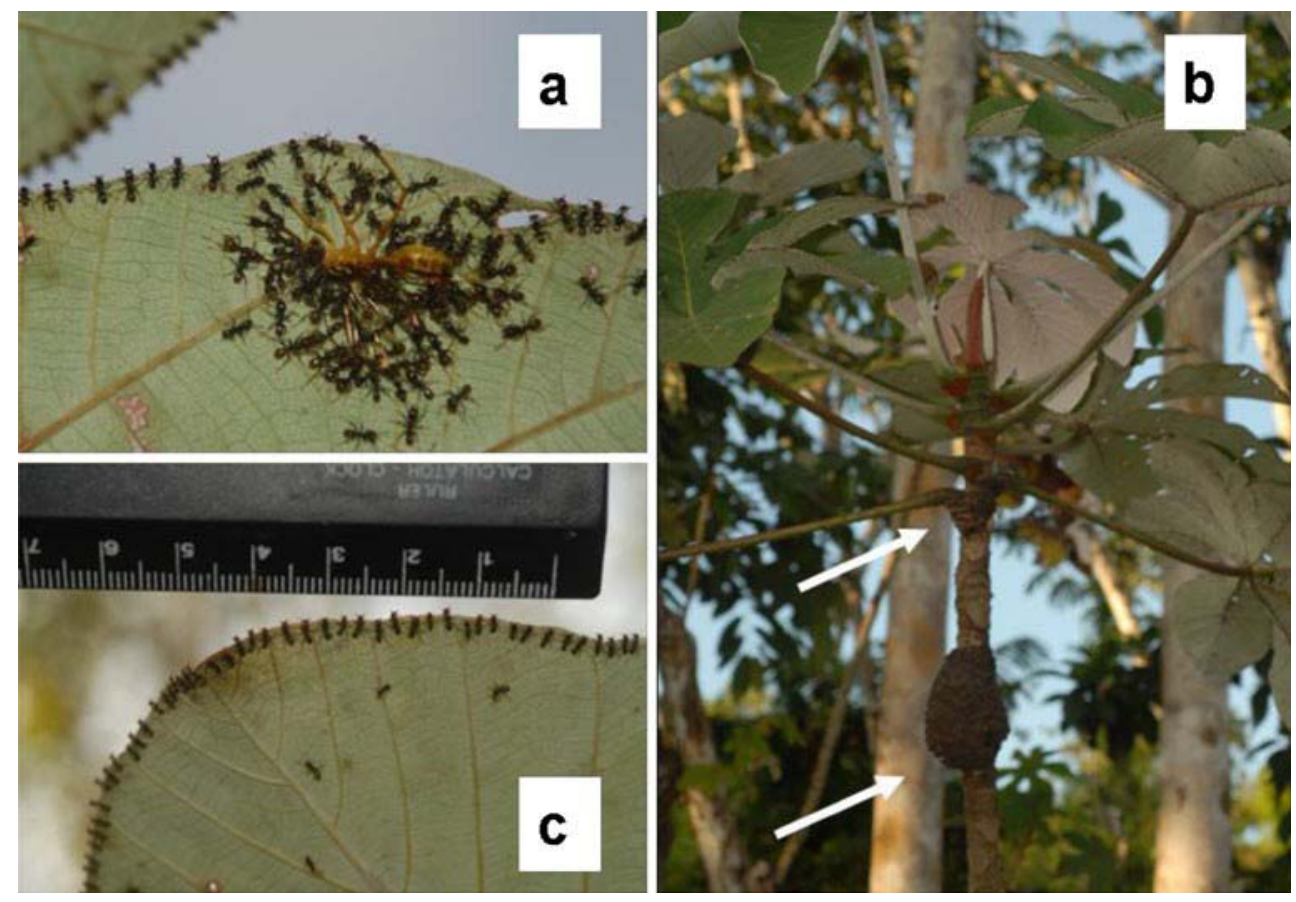
Azteca species due to the small size of the queens (Longino 2007; Guerrero et al. 2010), although this still remains to be demonstrated. In both temporary social parasitism and inquilism (or permanent parasitism), the queens are relatively small. In temporary social parasitism, the newly mated queens must find and sneak into a colony of the host species, and be adopted. Then, the original host queen is killed by the intruder or by her own workers. As the parasitic queen lays eggs and its brood develops into workers, there is an intermediary step consisting of a mixed parasite-host colony. Later, as the host workers are not replaced, the colony comes to consist entirely of the parasitic queen and her offspring (Hölldobler and Wilson 1990).

We sought to determine in this study if A. andreae is a true temporary social parasite of one or both Cecropia ants, if it is a parasite of the mutualism between these Azteca species and the myrmecophytic Cecropia, or both a temporary social parasite and a parasite of the mutualism. We therefore examined (1) the comparative number of C. obtusa and C. palmata sheltering A. andreae carton nests in the area studied, and if colonies can be sheltered by trees other than myrmecophytic Cecropia; (2) the size of the A. andreae colonies based on the size of their host tree, if the worker caste is polymorphic and if all kinds of workers are involved in hunting and thus play a role in protecting the plant foliage; (3) if young A. andreae colonies can form mixed colonies with A. alfari and/or A. ovaticeps (showing that A. andreae is a social parasite); (4) if A. andreae colonies protect their host Cecropia foliage from defoliators; and (5) if these colonies affect their host plant's fitness as evaluated through fruit production.

Materials and methods

Study site and model system

This study was conducted between 2004 and 2009 in secondary forest formations in French Guiana near the Petit Saut dam (5 $\left.03^{\prime} 39^{\prime \prime} \mathrm{N}-53^{\circ} 02^{\prime} 36^{\prime \prime} \mathrm{W}\right)$, along Route $\mathrm{N}^{\circ} 1$ between Kourou ( $\left.5^{\circ} 09^{\prime} 35^{\prime \prime} \mathrm{N}-52^{\circ} 39^{\prime} 01^{\prime \prime} \mathrm{W}\right)$ and Sinnamary ( $\left.5^{\circ} 22^{\prime} 60^{\prime \prime} \mathrm{N}-52^{\circ} 57^{\prime} 0^{\prime \prime} \mathrm{W}\right)$, along the road to Kaw Mountain (between $4^{\circ} 43^{\prime} 60^{\prime \prime} \mathrm{N}-52^{\circ} 17^{\prime} 60^{\prime \prime} \mathrm{W}$ and $4^{\circ} 38^{\prime} 20^{\prime \prime} \mathrm{N}-52^{\circ} 06^{\prime} 30^{\prime \prime} \mathrm{W}$ ), along the last kilometer of the dirt road leading to the Auberge des Chutes Voltaire $\left(5^{\circ} 29^{\prime} 27^{\prime \prime} \mathrm{N}-54^{\circ} 02^{\prime} 16^{\prime \prime} \mathrm{W}\right)$, and along $1 \mathrm{~km}$ of Route $\mathrm{N}$ ${ }^{\circ} 1$ west of Iracoubo $\left(5^{\circ} 28^{\prime} 60^{\prime \prime} \mathrm{N}-53^{\circ} 13^{\prime} 0^{\prime \prime} \mathrm{W}\right)$. We recorded a total of $145 \mathrm{~A}$. andreae nests for which the host tree was identified and measured. The location of each A. andreae colony was noted.

We first verified the number of A. andreae, A. alfari, and A. ovaticeps nests on 3,544 C. obtusa (widely distributed) and 1,432 C. palmata (restricted to the white sands found along coastal areas) more than $4.5 \mathrm{~m}$ in height growing alongside the roads. We then surveyed $105 \mathrm{C}$. obtusa near Kaw Mountain (where C. palmata is absent), and 129 C. palmata from an area situated west of the village of Iracoubo (white sands; C. obtusa is very rare). We incited the ants to leave the domatia by tapping the tree trunk with the flat side of the blade of a machete; we then used an aspirator to gather some of the workers for further identification. When, exceptionally, no workers left the domatia, we cut open the trees with the machete to gather the ants. Voucher specimens were deposited in the Laboratório de Mirmecologia, CEPEC-CEPLAC, Itabuna, Bahia, Brazil.

Because C. obtusa is dioecious, we verified if $\mathrm{A}$. andreae colonies shelter in both male and female trees during the period when the trees bear inflorescences (45 trees examined).

A. andreae colonies on trees other than myrmecophytic cecropia

As suggested by Longino (2007) for Azteca schimperi, another species in the aurita group, we hypothesized that A. andreae colonies can leave their host Cecropia tree to build a new nest on a non-Cecropia tree in the surroundings. We tried to trigger this phenomenon by cutting some leaves off of eight C. obtusa sheltering an A. andreae nest, and then verified if the colonies later moved to a nearby tree. Reciprocally, we connected the trunk of ten non-Cecropia trees sheltering an A. andreae nest (that had moved naturally or during the previous experiment) to that of a Cecropia situated in the area (1.5-6 m further away) using a branch whose extremities were attached to both trunks. Then, we cut several branches off of the host tree and verified after 4 weeks if the colony had moved to the Cecropia.

Size and composition of the A. andreae colonies

To estimate the population sizes of the A. andreae colonies, first we gathered nests from $25 \mathrm{C}$. obtusa trees. The carton nests plus the hollow tree branches were placed inside large plastic bags to ensure the capture of the maximum number of workers. The plastic bags were then transported to the laboratory, and placed in a refrigerator at $4^{\circ} \mathrm{C}$ for ca. $3 \mathrm{~h}$. To evaluate colony composition, the branches, and then the nests, were taken out of the refrigerator, completely opened, and we used smooth forceps to gather the numbed workers, winged sexuals, and queens and put them into a plastic vial containing $75^{\circ}$ ethanol. The individuals were counted all throughout the process. Also, 21 additional small A. andreae nests (smaller than $10 \times 6.5 \mathrm{~cm}$; height $\times$ diameter) 
and their host Cecropia trees were opened to look for the presence of mixed colonies.

In order to verify if polymorphism in the worker caste plays a role in the distribution of their tasks, we selected three C. obtusa sheltering a medium-sized A. andreae carton nest (colonies 12, 14, and 16 from Table 1) from which we cut two leaves whose margins were fringed with ambushing workers, and put them into a large plastic bag. We then gathered the nests and put each of them into a plastic bag. Transported to the laboratory, the plastic bags were placed in a refrigerator for ca. $3 \mathrm{~h}$ permitting us to randomly sample 500 workers from each nest, and 100 of the corresponding hunting workers from the leaves (or a total of 1500 and 300 workers, respectively). We weighed each worker with a microscale (Mettler ${ }^{\circledR}$ AE 260) and compared the mean weight $( \pm \mathrm{SE})$ of the workers from the two lots using the unpaired $t$ test.
Hunting plays a major role in the biology of A. andreae, as demonstrated by the fact that the margins of all of the leaves of a host tree are very frequently fringed with ambushing workers (Dejean et al. 2010). But just how many workers per colony are involved in this ambushing effort? In an attempt to answer that question, we used the three colonies mentioned above to compare the total number of workers per colony with the theoretical number of workers likely to hunt side-by-side beneath the margins of all of the leaves on each tree. To evaluate this theoretical number, we first calculated the density of the ambushing workers by placing a ruler ca. $1.5 \mathrm{~cm}$ from the leaf margins and photographed the ants (Fig. 1c) resulting in ca. 4.4 workers per $\mathrm{cm}(\mathrm{N}=80$; Dejean et al. 2010). We then cut off all of the leaves from each corresponding tree to measure the length of their margins using a measuring tape. The total length of the leaf margins and the density of the

Table 1 Composition of the colonies according to the size of their nests and of their host trees

Size of the colonies and their host trees

\begin{tabular}{|c|c|c|c|c|c|c|c|c|}
\hline & No. workers & No. males & $\begin{array}{l}\text { No. winged } \\
\text { females }\end{array}$ & $\begin{array}{l}\text { Physogastric queen } \\
\text { presence }\end{array}$ & $\begin{array}{l}\text { Size of the nests } \\
(\mathrm{h} \times \mathrm{lcm})\end{array}$ & $\begin{array}{l}\text { Height of } \\
\text { trees (m) }\end{array}$ & No. leaves & $\begin{array}{l}\text { No. Azteca ovaticeps } \\
\text { workers }\end{array}$ \\
\hline 1 & 30,899 & 6,888 & 1,468 & Yes & $31 \times 15$ & 19 & 55 & - \\
\hline 2 & 22,600 & Pupae & Pupae & Yes & $16.5 \times 13.5$ & 7 & 22 & - \\
\hline 3 & 22,240 & 255 & 840 & Yes & $17 \times 12$ & 18 & 35 & - \\
\hline 4 & 21,200 & 0 & 0 & Yes & $15 \times 13$ & 6 & 7 & - \\
\hline 5 & 19,019 & & 0 & Yes & $17 \times 10.5$ & 15 & 33 & - \\
\hline 6 & 18,900 & 0 & 0 & Yes & $10 \times 9+5 \times 3$ & 7 & 7 & - \\
\hline 7 & 18,250 & 521 & 1 & Yes & $17.5 \times 12.5$ & 6 & 6 & - \\
\hline 8 & 15,230 & 79 & 16 & Yes & $16.5 \times 11.5$ & 11 & 28 & - \\
\hline 9 & 14,990 & 0 & 0 & Yes & $14.5 \times 12$ & 10 & 8 & - \\
\hline 10 & 11,500 & 46 & 0 & Yes & $15 \times 11.5$ & 7 & 27 & - \\
\hline 11 & 10,550 & 0 & 0 & Yes & $11.5 \times 6.5$ & 6 & 8 & - \\
\hline 12 & 9,800 & 64 & 0 & Yes & $10 \times 5$ & 6 & 10 & - \\
\hline 13 & 8,360 & 61 & 0 & ? & $18 \times 10$ & 13 & 23 & - \\
\hline 14 & 6,015 & 0 & 0 & Yes & $14 \times 10.5$ & 7 & 29 & - \\
\hline 15 & 5,950 & 0 & 1 pupae & Yes & $6.5 \times 5$ & 6 & 14 & 133 \\
\hline 16 & 5,750 & 0 & 0 & Yes & $11 \times 8$ & 7 & 18 & - \\
\hline 17 & 5,660 & 0 & 0 & Yes & $9 \times 5.5$ & 6 & 7 & 510 \\
\hline 18 & 5,620 & 0 & 0 & Yes & $7.5 \times 4.5$ & 4.5 & 29 & - \\
\hline 19 & 5,370 & 2 & 1 & Yes & $9 \times 6.5$ & 7 & 32 & 690 \\
\hline 20 & 4,740 & 0 & 0 & Yes & $8 \times 5$ & 5 & 11 & 312 \\
\hline 21 & 4,314 & 1 & 1 & Yes & $9 \times 6.5$ & 6 & 9 & - \\
\hline 22 & 4,200 & 0 & 0 & Yes & $8 \times 6.5$ & 15 & 37 & - \\
\hline 23 & 4,101 & 1 & 0 & Yes & $7 \times 5.5$ & 12 & 5 & - \\
\hline 24 & 2,280 & 0 & 0 & Yes & $7.4 \times 4.6$ & 5 & 9 & - \\
\hline 25 & 2,192 & 1 & 0 & Yes & $8 \times 6$ & 6 & 13 & 64 \\
\hline
\end{tabular}

Each nest plus hollow internodes were gathered from the host trees, put into plastic bags, transported to the laboratory, and put into a refrigerator for ca. $3 \mathrm{~h}$. Then, the nests and internodes were completely opened in the laboratory, and the individuals counted by the co-authors 
ambushing workers permitted us to obtain their theoretical number.

Impact of A. andreae on their host tree foliage and fitness

We compared the defoliation of C. obtusa trees of similar sizes and sheltering different ant species during two surveys conducted 9 months apart. The results were very similar, so that we present only those from the second survey. Indeed, these results give us an idea of the history of the defoliation over the preceding ca. 18 months corresponding to the lifespan of the C. obtusa leaves (noted by tagging young leaves; $\mathrm{AD}$, personal observation). The surveys were conducted in May 2007 between Kourou and Sinnamary during "normal" conditions involving several defoliating insects prone to attacking the leaves, but generally expulsed by the workers when discovered, and in June 2008 along the road to Kaw Mountain during a proliferation of Dircema nigripenne (Chrysomelidae: Galerucinae). Like for some other galerucine species (Jolivet 1996), the larvae can live and feed on Azteca-inhabited Cecropia trees.

We defined four levels of defoliation (when present, the youngest, still red-brown leaves were not taken into consideration): (1) not attacked: leaves intact or only defoliated to less than $5 \%$ of their surface; (2) slightly attacked: several leaves were attacked, and $10 \%$ to $50 \%$ of their surface was destroyed; (3) somewhat attacked: ca. all of the leaves were attacked, and $10 \%$ to $50 \%$ of their surface was destroyed; and (4) very attacked: all of the leaves were attacked, and more than $50 \%$ of their surface was destroyed. The results were compared using the Kruskal-Wallis test followed by a Dunn's post hoc test for multiple comparisons.

To evaluate the impact of the compared ant species on the fitness of the trees, we used direct observation to study fruit production by the 3,544 C. obtusa more than $4.5 \mathrm{~m}$ tall growing alongside the roads.
For statistical comparisons (Chi-square test, unpaired $\mathrm{t}$ test, Kruskal-Wallis and Dunn's tests), we used GraphPad Prism 4.03 software.

\section{Results}

Tree species hosting A. andreae colonies

Only a small percentage of the Cecropia spp. trees sheltered A. andreae. During the first series of observations, we noted 77 out of 3,544 (2.17\%) and eight out of 1,432 $(0.56 \%)$ A. andreae nests on C. obtusa and C. palmata, respectively; the difference is significant $\left(\mathrm{X}_{\text {Yates }}{ }^{2}=14.88\right.$; $\mathrm{P}<0.0001)$. The in-depth survey conducted in Iracoubo and at Kaw Mountain also showed that significantly more A. andreae nests are sheltered by C. obtusa than by C. palmata $\left(\mathrm{X}_{\text {Yates }}{ }^{2}=46.53 ; 6 \mathrm{df} ; \mathrm{P}<0.0001\right.$ ), while we noted six ant species likely to shelter in the hollow branches of C. palmata and C. obtusa (Fig. 2). When the trees bore inflorescences, we noted that A. andreae nested similarly on male and female Cecropia (23 installed on males, 22 on females; $\mathrm{N}=45$ ).

Out of the $145 \mathrm{~A}$. andreae nests recorded in total during this 6-year-long study, all but nine (93.8\%) were found on a C. obtusa or a C. palmata whose height varied from $4.5 \mathrm{~m}$ to ca. $25 \mathrm{~m}$. We noted $35.9 \%$ of the A. andreae nests on Cecropia $4.5-8 \mathrm{~m}$ tall, $27.6 \%$ on trees $8-12 \mathrm{~m}$ tall, $17.9 \%$ on trees $12-16 \mathrm{~m}$ tall, and $12.4 \%$ on trees $16-$ $25 \mathrm{~m}$ tall. The latter case corresponds to the tallest ca. 30year-old trees that sheltered the largest carton nests containing numerous winged sexuals (see tree No. 1 in Table 1). Although the nests are rebuilt as the trees grow (Fig. 1b), this shows that the association can likely persist for a long time. The nine non-Cecropia trees bearing an A. andreae colony belonged to different species frequently found in pioneer formations (i.e., Chrysophyllum argen-
Fig. 2 The different ant species sheltered by Cecropia palmata $(\mathrm{N}=105)$ and Cecropia obtusa $(\mathrm{N}=129)$. Azteca sericeasur is a polydomous nesting species whose queens nest in live stems, near the base, while workers and brood are found in carton pavilions where they also attend hemipterans (Longino 2007). Camponotus balsami and Daceton armigerum also nest in hollow branches; the former, nocturnal, is frequent in pioneer formations; while the latter, diurnal, is rather a canopy species

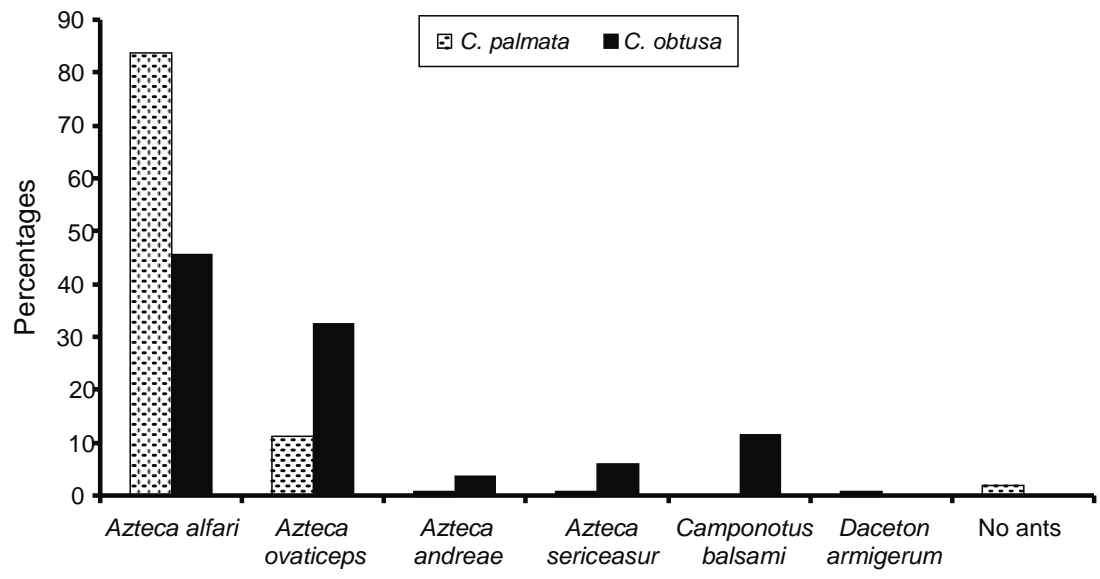


teum, Sapotaceae; Miconia sp. and Bellutia sp., Melastomataceae; Vismia guianensis, and V. latifolia Clusiaceae).

Azteca andreae colonies moving to trees other than myrmecophytic Cecropia

We witnessed five cases where there was the progressive occupation of the foliage of the trees surrounding a C. obtusa bearing an A. andreae colony, and then the beginning of the construction of a new nest on one of these trees. In all cases, the host Cecropia had lost branches due to an accidental event. The workers continued to hunt on the foliage of the abandoned Cecropia tree as well as on the new host tree and the surrounding vegetation; the same was true for their exploitation of hemipterans.

We successfully reproduced this phenomenon by cutting several leaves off of eight $C$. obtusa. The same result was obtained by cutting several leaves off of 10 non-Cecropia trees sheltering an A. andreae nest (four had moved naturally, the six others belong to the previous experiment) whose trunks were connected with those of a neighboring C. obtusa using a long branch. In both experiments, the new nests were built in ca. 3 weeks.

Size and composition of A. andreae colonies, and the search for the host Azteca species

The largest A. andreae nest contained a physogastric queen (i.e., whose gaster was swollen because the ovaries were enlarged), more than 30,000 workers, numerous eggs, larvae and pupae, and winged sexuals (Table 1). The presence of a physogastric queen (see photo in Guerrero et al. 2010), was recorded in 24 out of the 25 nests, plus five other nests opened during preliminary studies.

Five among the smallest A. andreae nests also contained A. ovaticeps workers but no queen from this species (Table 1), pointing to the existence of mixed colonies. We therefore opened 21 additional small A. andreae nests, and noted the occurrence of A. ovaticeps workers in 16 of them, resulting in a total of 21 mixed $\mathrm{A}$. ovaticeps-A. andreae colonies recorded. In no case was the co-occurrence of A. alfari and A. andreae workers detected.

To test the hypothesis that $\mathrm{A}$. andreae is an exclusive parasite of $\mathrm{A}$. ovaticeps, we estimated the probability, $\mathrm{p}$, that A. andreae parasitizes A. alfari, based on our data. We first assumed that A. andreae parasitizes A. alfari or A. ovaticeps according to a Bernoulli process with parameter p. This assumption implied that A. alfari and A. ovaticeps colonies were randomly distributed among C. obtusa trees and with similar abundances. Hence, $\mathrm{K}$, the number of $\mathrm{A}$. alfari colonies parasitized among the $\mathrm{N}$ colonies parasitized by A. andreae followed a binomial distribution with parameters $\mathrm{N}$ and $\mathrm{p}$. Taking into account the data $(\mathrm{x}=0$ and $n=21$ ), the likelihood of the parameter, $p$, was then given by $L(p ; x=0, n=21)=(1-p)^{\wedge} 21$. According to Bayes' formula, the density, $\mathrm{f}$, of the probability distribution of $\mathrm{p}$ conditionally to the data is proportional to $L(p ; x=0, n=21)$. As the integrate of a density function equals one, we had to normalize $L$ by its integral over [0;1] (equal to1/22) to get $\mathrm{f}$ $(p \mid x=0 ; n=21)=\left((1-p)^{\wedge} 21\right)^{*} 22$. From $f$ we computed the usual estimators of $\mathrm{p}$ : mean $=0.0435$, median $=0.0310$ and the 95th confidence interval [0; 0.1273]. Because the abundance of $\mathrm{A}$. alfari and A. ovaticeps colonies was assumed to be similar in our model even though A. alfari is more frequent than A. ovaticeps (Fig. 2), the estimators for $\mathrm{p}$ were conservative. It is therefore likely that A. andreae only parasitizes A. ovaticeps.

Note that during earlier studies examining the territoriality of A. alfari and A. ovaticeps, we found four mixed A. andreae-A. ovaticeps colonies sheltering in the hollow trunks of young $\mathrm{C}$. obtusa trees that we interpreted to be the step before the construction of an external, carton nest by A. andreae workers. While A. ovaticeps workers gathered FBs, A. andreae workers ignored them.

Hunting workers and polymorphism in the worker caste

Through their mean weight, we also noted that hunting workers are significantly heavier (and larger) than those gathered from inside the nests and belonging to the internal service: $1.393 \pm 0.0197 \mathrm{mg}(\mathrm{N}=300)$ versus $0.68 \pm 0.011(\mathrm{~N}=$ 1500); unpaired t test: $\mathrm{t}=26.8 ; 1798 \mathrm{df} ; \mathrm{P}<0.0001$.

After observing three Cecropia trees sheltering an A. andreae colony during several days and noting which leaves had their entire margin occupied by ambushing workers, we cut off these leaves, measured the total length of their margins and evaluated the number of workers likely to hunt on them based on 4.4 workers per $\mathrm{cm}$. Compared to the total number of workers in the colonies, we noted that up to $85.2 \%$ of the workers can be involved in ambushing side-by-side (colony 10 from Table 1: 8350 ambushing workers versus 9800 workers in total, $85.2 \%$; colony 12 : 4800 versus 6015, 79.8\%; colony 14: 4300 versus 5750, $74.8 \%)$.

Also, the sum of the margins of all of the leaves on the tree (or the total length of the leaf margins) will determine the maximum number of workers that can hunt at one time. In most of the cases, the total number of workers in the colony was lower than the theoretical number of workers that can ambush side-by-side along the total length of the leaf margins of the corresponding trees. Thus, the hunting workers ambushed along the margins of only a part of their host tree leaves (Fig. 3). This is particularly true for A. andreae colonies having likely colonized large trees (horizontal series of diamonds; Fig. 3). On the contrary, when the total number of workers 


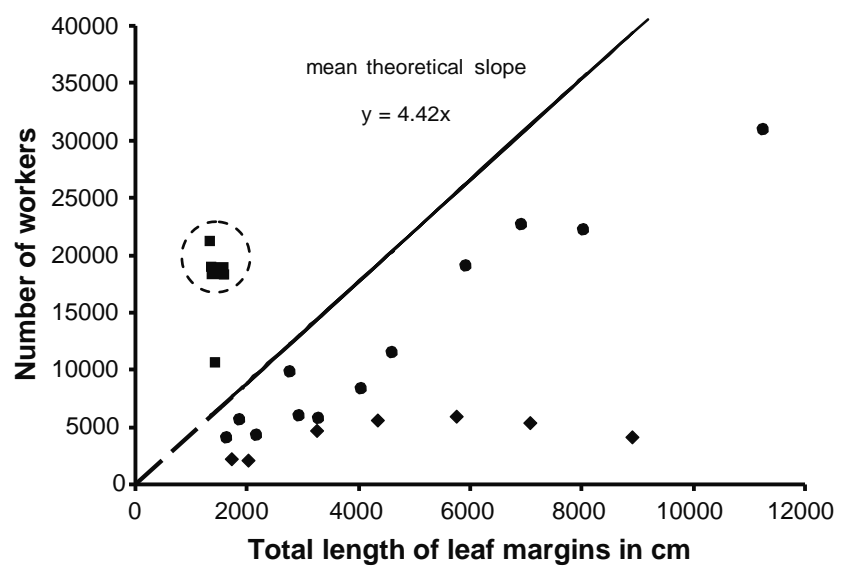

Fig. 3 Ratio between the number of workers in 23 nests opened and the total length of the leaf margins available in each case. The mean theoretical slope corresponds to the number of workers that can hunt side-by-side along the total length of the leaf margins based on 4.4 ants per $\mathrm{cm}$. Three groups of colonies can be distinguished. For the four colonies situated above the slope (squares), particularly the threecircled, part of the workers foraged on the surrounding foliage. For the colonies below the slope, the workers only occupy a fraction of the total length of the leaf margins when ambushing. The number of workers is correlated to the total length of the leaf margins for the colonies represented by a circle. They likely correspond to colonies whose size increased with that of the host trees. Colonies represented by diamonds correspond to small colonies nesting on comparatively large trees; they probably parasitized large Azteca ovaticeps colonies

in the colony was by far superior to this theoretical number, a part of the hunting workers ambushed for prey on the foliage of the surrounding plants, something noted for the three colonies circled in Fig. 3 (corresponding to colonies Nos. 4, 6 and 7 in Table 1).

We experimentally reproduced this situation by cutting off three leaves from each of eight Cecropia trees bearing an A. andreae nest. After 4 days, some of the hunting workers ambushed on the foliage of the surrounding vegetation (that they had reached from the ground), illustrating a relationship between the size of the colony and the total length of the leaf margins. Later, they also attended hemipterans on the surrounding trees.

Relationship between the size of A. andreae colonies and the size of the host trees

The smallest tree bearing an external A. andreae carton nest was $4.5 \mathrm{~m}$ tall, indicating that colonization probably began while the host A. ovaticeps colony was relatively populous. Later, as the trees grow, the workers build new nests just under the new crowns using materials from the old nest whose size decreases as a result (see nest $\mathrm{N}^{\circ} 5$, Table 1; Fig. 1c).

The scatter plot displaying the relationship between the number of workers per colony and the size of the host tree (Fig. 4) shows a positive relationship for 18 out of the 25 A. andreae colonies. A cluster of outliers is represented by

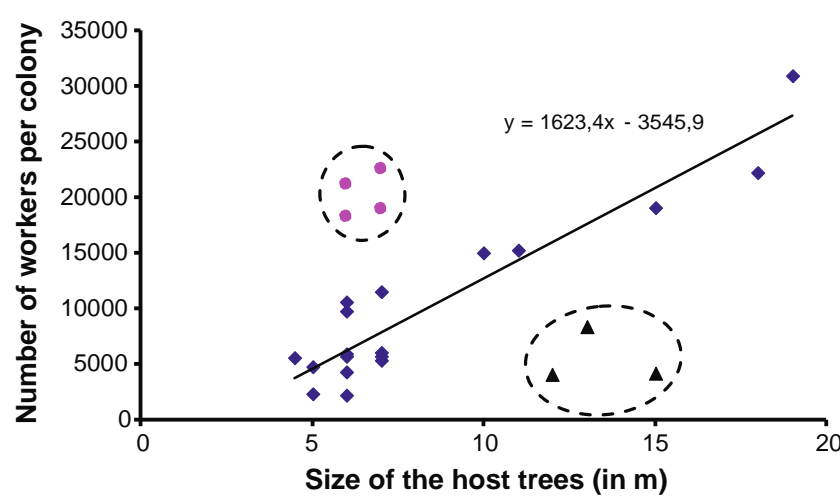

Fig. 4 Scatter plot illustrating the relationships between the number of workers per colony and the size of the host tree (diamonds). The four colonies represented by circles correspond to nests installed on relatively small trees, while the three colonies represented by triangles correspond to small nests installed on relatively tall trees

four large colonies installed on relatively small trees (corresponding to Nos. 2, 4, 6, 7 in Table 1), but tree No. 2, which has several branches and numerous leaves, rather belongs to the previous case. The second cluster of outliers is represented by three small colonies sheltering on relatively tall trees (corresponding to Nos. 13, 22, 23 in Table 1). Except for tree No. 23 with only five leaves (in certain cases, the trees have a fast vertical growth), this might indicate that $\mathrm{A}$. andreae can colonize even relatively large A. ovaticeps colonies sheltering on large trees.

Impact of A. andreae on their host tree foliage and fitness

Unexpectedly, C. obtusa individuals sheltering A. andreae colonies were significantly less defoliated than all of the others, whatever ant species they sheltered (Fig. 5). This was true both during 'normal conditions' and during a proliferation of the galerucine chrysomelid D. nigripenne, which is a Cecropia defoliator whose larvae are well adapted to the presence of A. alfari and A. ovaticeps.

While verifying the impact of A. andreae on the fitness of C. obtusa, we noted significantly more fruits on trees more than $4.5 \mathrm{~m}$ tall sheltering A. andreae colonies than on those sheltering an A. alfari or an A. ovaticeps colony (the two latter species pooled; the tree size distribution is similar): $52.25 \%$ $(\mathrm{N}=77)$ versus $28.32 \%(\mathrm{~N}=3467) ; \mathrm{X}_{\text {Yates }}^{2}=11.61 ; \mathrm{P}<0.001$.

\section{Discussion}

Parasitism of the Azteca-Cecropia mutualisms versus the social parasitism of Cecropia ants

In this study we show that A. andreae, whose colonies build carton nests on myrmecophytic Cecropia, is not a parasite of Azteca-Cecropia mutualisms, but a temporary 


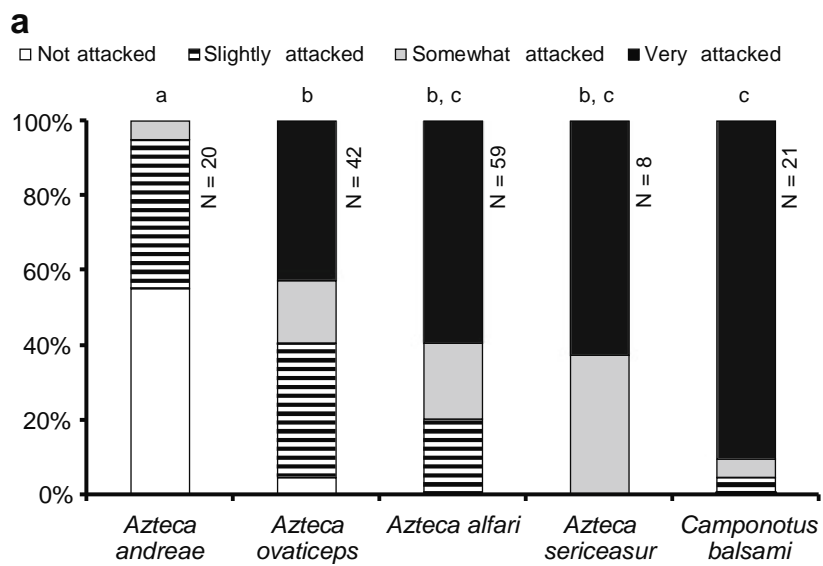

b

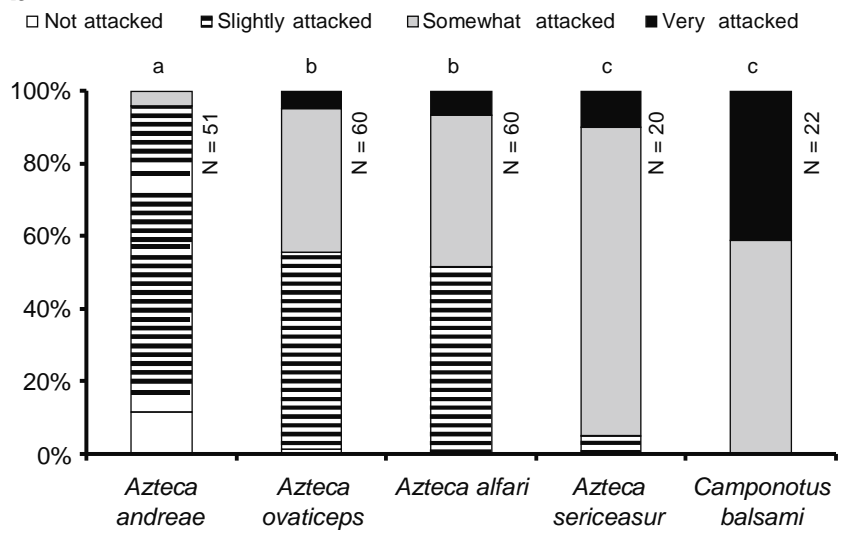

Fig. 5 Percentage of defoliation of $8-10$-m-tall Cecropia obtusa according to the ant species sheltered. a Percentage of defoliation during "normal" conditions involving several defoliating insects such as adult locusts including large individuals, and several chrysomelid species that are generally attacked or intimidated by Azteca workers. b Percentage of defoliation during a proliferation of Dircema nigripenne, a galerucine chrysomelid. Statistical comparisons. Kruskal-Wallis test: $\mathrm{H}_{150}{ }^{4}=88.49$ and $\mathrm{H}_{213}{ }^{4}=57.25$ for a and b, respectively; $\mathrm{P}<0.0001$ in both cases. Dunn's post hoc test: different letters indicate significant differences at $\mathrm{P}<0.01$

social parasite of A. ovaticeps, one of the two mutualistic Azteca species of myrmecophytic Cecropia growing in the area studied. Indeed, parasites of plant-ant/myrmecophyte mutualisms colonize the myrmecophytes, but without providing them with a 'reciprocal' service (generally in the form of protection from defoliating insects). Because of major defoliation, these myrmecophytes are also affected in their fitness as they produce fewer seeds than individuals sheltering the appropriate plant-ants (Fischer et al. 2002; Heil and McKey 2003; Heil et al. 2004; Rico-Gray and Oliveira 2007).

Here we show that, contrarily to parasites of the mutualisms, A. andreae colonies protect their host Cecropia trees more efficiently than do A. alfari or A. ovaticeps. This was particularly true during the proliferation of a special- ized chrysomelid beetle that is tolerated by A. alfari and A. ovaticeps in the area studied (see also Jolivet 1996), whereas it is eliminated by A. andreae workers. This protective action appears to be a by-product of the very effective group ambushing behavior of A. andreae workers permitting them to capture large insects (Dejean et al. 2010) and to the frequent presence of numerous workers ambushing on their host tree foliage (this study). This compensates the absence of purely defensive behavior and of an induced defense in A. andreae as opposed to A. alfari and A. ovaticeps (Dejean et al. 2008, 2009). Also, A. andreae does not affect the host tree's fitness; on the contrary, Cecropia trees bearing A. andreae nests produced more fruits than those associated with Cecropia ants.

\section{A. andreae as a social parasite of Azteca ovaticeps}

Occurrences of social parasitism are poorly documented for inter-tropical and sub-tropical ant faunas (Hölldobler and Wilson 1990). Most of the rare cases of Neotropical social parasites reported correspond to inquiline ants as the small queens were found while opening the nests of their host Acromyrmex (Sumner et al. 2004; De Souza et al. 2007), Ectatomma (Feitosa et al. 2008), Pheidole (Wilson 1984, 2003), Pseudomyrmex (Ward 1996), and Solenopsis (Calcaterra et al. 1999) species. The existence of temporary social parasites has been shown in two Pseudomyrmex species: small queens and colonies mixed with a host species (Ward 1996). Concerning the aurita group of Azteca, only the small queens provide an indication that the group is likely composed of social parasites (Longino 2007; Guerrero et al. 2010), something now demonstrated in this study for A. andreae, and explaining why this species is relatively infrequent. Although A. alfari is very frequently found in the same areas, A. andreae seems to exclusively parasitize A. ovaticeps with which it forms intermediate, mixed colonies. We found no A. ovaticeps workers after the A. andreae colonies reached a size of ca. 6,000 workers, whereas A. andreae individuals were no longer noted inside the domatia. It is likely that they are unable to recognize as such the prostomata, or thinner areas only recognizable to the founding queens and workers of Cecropia ants (Davidson 2005).

In general, when the abiotic conditions support Cecropia tree growth, the A. andreae workers limit their foraging activities to its foliage and can reach a large colony size and produce sexuals (see nest No. 1 in Table 1). Yet, when host tree development is slowed down due to exceptional conditions such as soil exhaustion, excessive dryness or the accidental breaking off of branches, the workers may be led to attend hemipterans and hunt on surrounding plants. The colonies can even move, and the workers build a new nest on a tree that can be a plant other than Cecropia; some 
of these characteristics have been noted for A. schimperi (Longino 2007). Therefore, A. andreae is not an entirely obligate Cecropia inhabitant as are the mutualist Azteca species, and when their host Cecropia tree dies accidentally they are able to move to another tree nearby and so to persist. Yet, these cases remain exceptional and most A. andreae colonies grow as their host Cecropia tree grows. Also, when moving to a tree other than Cecropia, it becomes more difficult for A. andreae to easily catch large prey as the Cecropia leaves are larger than those of other trees in the area permitting numerous workers to ambush at one time, and their underside is particularly downy. This velvet-like structure combines with the hook-shaped claws of the A. andrea workers to act like a natural Velcro ${ }^{\circledR}$ that reinforces the group ambush strategy, allowing the workers to capture insects of up to 13,350 times their mean weight (Dejean et al. 2010).

As a social parasite of A. ovaticeps, however, A. andreae still takes the place of a true mutualist, so that one can wonder if the reduced herbivory and resulting higher fruit production that appears to be a by-product of its hunting behavior, does not hide other benefits furnished by true mutualistic Azteca species. Indeed, after the intermediate, mixed colony phase with A. ovaticeps, the A. andreae colonies build a carton nest, and then no longer use the Cecropia domatia. As such, the host Cecropia trees lose a part of the benefits they gain from their true mutualistic Azteca species: the provision of nutrients as noted for C. peltata (another myrmecophytic Cecropia) for which $93 \%$ of the nitrogen is derived from debris deposited in the domatia by its guest Azteca ants (Sagers et al. 2000). Plant-ants can supply myrmecophytes with nutrients. Beattie (1989) called this phenomenon "myrmecotrophy". This trait has major importance when nutrient availability is low, explaining why myrmecotrophy is frequent in epiphytes (Beattie 1989; Rico-Gray and Oliveira 2007). Because the level of nutrient availability for geophytes growing on poor tropical soils is also low and exacerbated further when sequestrated by competing plants, myrmecotrophy has also been noted for myrmecophytic geophytes. This is the case for Malaysian rattan palms (Rickson and Rickson 1986), neotropical Melastomataceae (Cabrera and Jaffe 1994; Solano and Dejean 2004), Piper (Fischer et al. 2003), and Cecropia (Sagers et al. 2000). Therefore, the advantages that ants provide to their host myrmecophytes are notably greater when myrmecotrophy is added to biotic defence.

\section{Nest-site selection}

Nest-site selection by founding A. andreae queens implies that they find a Cecropia tree (there are two suitable species in the area studied) inhabited by the appropriate Azteca species. In the cases where this has been studied, the specificity of plant-ants for one myrmecophyte species is due to the genetically-determined attraction of founding queens toward this species, while in 'generalist' arboreal ants a familiarization process (contact with other plants during development) can override this genetically-determined attraction (Djiéto-Lordon and Dejean 1999a, b).

It is likely that the selection of adequate Cecropia trees by founding $\mathrm{A}$. andreae queens is genetically determined; otherwise, the queens produced by colonies having moved to another tree species would be unable to select Cecropia due to the absence of an adequate familiarization process. The same is true for the selection of A. ovaticeps colonies (rather than A. alfari), as winged sexuals develop a long time after the mixed colony phase and so are never in contact with A. ovaticeps individuals (or only exceptionally; see colony 13, Table 1). The higher number of $\mathrm{A}$. andreae colonies sheltered by C. obtusa can be explained by the fact that more A. ovaticeps are associated with this tree species than with C. palmata (Fig. 2).

In conclusion, we show that $\mathrm{A}$. andreae is a temporary social parasite of the plant-ant A. ovaticeps, but is not a parasite of the Azteca-Cecropia mutualism. Indeed, (1) the workers do not take advantage of the rewards furnished by the host Cecropia, (2) contrarily to Cecropia ants, they can forage on other trees and their colonies can move, and (3) they even provide their host Cecropia with better protection from defoliators than do Cecropia ants, while enhancing their fitness. Two aspects of the biology of A. andreae are especially notable: its predatory strategy involving up to $85 \%$ of the colony's population of workers; and, like for plant-ants, nest-site selection is likely genetically determined with the life cycle obligatorily passing through an association with myrmecophytic Cecropia (and an adequate host-ant colony).

Acknowledgements We are grateful to Shawn M. Clark (Brigham Young University, Provo, Utah, USA) for the identification of the chrysomelid beetles, to Marie-Françoise Prévost (Herbier de Guyane, Cayenne, France) for the identification of the plants, and to Andrea Yockey-Dejean for proof-reading the manuscript. Financial support for this study was provided by the Programme Amazonie II of the French Centre National de la Recherche Scientifique (project 2ID) and the Programme Convergence 2007-2013, Région Guyane from the European Community (project DEGA). The experiments comply with the current laws of the country in which they were performed. The authors declare that they have no conflict of interest.

\section{References}

Beattie A (1989) Myrmecotrophy: plants fed by ants. Trends Ecol Evol 4:172-176

Bronstein JL (2001) The exploitation of mutualisms. Ecol Lett 4:277287 
Cabrera M, Jaffe K (1994) A trophic mutualism between myrmecophytic melastomataceae Tococa guianensis Aublet and an Azteca ant species. Ecotropicos 7:1-10

Calcaterra LA, Briano JA, Williams DF (1999) Field studies of the parasitic ant Solenopsis daguerrei (Hymenoptera: Formicidae) on fire ants in Argentina. Environ Entomol 28:88-95

Clement LW, Köppen SCW, Brand WA, Heil M (2008) Strategies of a parasite of the ant-Acacia mutualism. Behav Ecol Sociobiol 62:953-962

Davidson DW (2005) Cecropia and its biotic defenses. Fl Neotrop Monog 94:214-226

De Souza DJ, Fernandes Soares M, Castro Della Lucia TM (2007) Acromyrmex ameliae sp. n. (Hymenoptera: Formicidae): a new social parasite of leaf-cutting ants in Brazil. Insect Sci 14:251-257

Dejean A, Corbara B, Orivel J, Leponce M (2007) Rainforest canopy ants: the implications of territoriality and predatory behavior. Funct Ecosyst Commun 1:105-120

Dejean A, Grangier J, Leroy C, Orivel J (2008) Host plant protection by arboreal ants: looking for a pattern in locally induced responses. Evol Ecol Res 10:1225-1240

Dejean A, Grangier J, Leroy C, Orivel J (2009) Predation and aggressiveness in host plant protection: a generalization using ants of the genus Azteca. Naturwissenschaften 96:57-63

Dejean A, Leroy C, Corbara B, Roux O, Céréghino C, Orivel J, Boulay R (2010) Arboreal ants use the "Velcro ${ }^{\circledR}$ Principle" to capture very large prey. PLoS ONE 5:e11331

Djiéto-Lordon C, Dejean A (1999a) Innate attraction supplants experience during host plant selection in an obligate plant-ant. Behav Proc 46:181-187

Djiéto-Lordon C, Dejean A (1999b) Tropical arboreal ant mosaic: innate attraction and imprinting determine nesting site selection in dominant ants. Behav Ecol Sociobiol 45:219-225

Feitosa RM, Hora RR, Delabie JHC, Valenzuela J, Fresneau D (2008) A new social parasite in the ant genus Ectatomma F. Smith (Hymenoptera, Formicidae, Ectatomminae). Zootaxa 1713:47-52

Fischer RC, Richter A, Wanek W, Mayer V (2002) Plants feed ants: food bodies of myrmecophytic Piper and their significance for the interaction with Pheidole bicornis ants. Oecologia 133:186-192

Fischer RC, Wanek W, Richter A, Mayer V (2003) Do ants feed plants? A ${ }^{15} \mathrm{~N}$ labelling study of nitrogen fluxes from ants to plants in the mutualism of Pheidole and Piper. J Ecol 91:126-134

Gaume L, McKey D (1999) An ant-plant mutualism and its hostspecific parasite: activity rhythms, young leaf patrolling, and effects on herbivores of two specialist plant ants inhabiting the same myrmecophyte. Oikos 84:130-144

Guerrero RJ, Delabie JHC, Dejean A (2010) Taxonomic contribution to the aurita group of the ant genus Azteca (Formicidae: Dolichoderinae). J Hymenopt Res 19:51-65
Heil M, McKey D (2003) Protective ant-plant interactions as model systems in ecological and evolutionary research. Ann Rev Ecol Syst Evol 34:425-553

Heil M, Baumann B, Krüger R, Linsenmair KE (2004) Main nutrient compounds in food bodies of Mexican Acacia ant-plants. Chemoecology 14:45-52

Heil M, González-Teuber M, Clement LW, Kautz S, Verhaagh M, Silva Bueno JC (2009) Divergent investment strategies of Acacia myrmecophytes and the coexistence of mutualists and exploiters. Proc Natl Acad Sci USA 106:18091-18096

Hölldobler B, Wilson EO (1990) The ants. Springer-Verlag, Berlin

Janzen DH (1975) Pseudomyrmex nigropilosa: a parasite of a mutualism. Science 188:936-937

Jolivet P (1996) Ants and plants: an example of coevolution. Backhuys, The Hague

Kautz SHT, Ward PS, Heil M (2009) How to prevent cheating: a digestive specialization ties mutualistic plant-ants to their antplant partners. Evolution 63:839-853

Longino JT (2007) A taxonomic review of the genus Azteca (Hymenoptera: Formicidae) in Costa Rica and a global revision of the aurita group. Zootaxa 1491:1-63

Raine N, Gammans N, Macfadyen IJ, Scrivner GK, Stone GN (2004) Guards and thieves: antagonistic interactions between two ant species coexisting on the same ant plant. Ecol Entomol 29:345352

Rickson FR, Rickson MM (1986) Nutrient acquisition facilitated by litter collection and ant colonies on two Malaysian palms. Biotropica 18:337-343

Rico-Gray V, Oliveira P (2007) The ecology and evolution of antplant interactions. The University of Chicago Press, Chicago

Sagers CL, Ginger SM, Evans RD (2000) Carbon and nitrogen isotopes trace nutrient exchange in an ant-plant mutualism. Oecologia 123:582-586

Solano PJ, Dejean A (2004) Ant-fed plants: comparison between three geophytic myrmecophytes. Biol J Linn Soc 83:433-439

Sumner S, Aanen DK, Delabie JHC, Boomsma JJ (2004) The evolution of social parasitism in leaf-cutting ants. Insect Soc 151:37-42

Ward PS (1996) A new workerless social parasite in the ant genus Pseudomyrmex (Hymenoptera: Formicidae), with a discussion of the origin of social parasitism in ants. Syst Entomol 21:253-263

Wilkinson DM, Sherratt TN (2001) Horizontally acquired mutualisms, an unsolved problem in ecology. Oikos 92:377-384

Wilson EO (1984) Tropical social parasites in the ant genus Pheidole, with an analysis of the anatomical parasitic syndrome (Hymenoptera: Formicidae). Insect Soc 31:316-334

Wilson EO (2003) Pheidole in the New World. A dominant, hyperdiverse ant genus. Harvard University Press, Cambridge 